\title{
PENGARUH VARIASI FLUIDA PENDINGIN TERHADAP CAPAIAN SUHU OPTIMAL PADA RANCANGAN MESIN PENDINGIN MINI WATER CHILLER
}

\author{
P. Deva Supriana ${ }^{1}$, K. Rihendra Dantes ${ }^{1}$, I N. Pasek Nugraha ${ }^{2}$ \\ Jurusan Pendidikan Teknik Mesin, Fakultas Teknik dan Kejuruan \\ Universitas Pendidikan Ganesha \\ Singaraja, Indonesia \\ e-mail : putudevasupriana@gmail.com, rihendra-dantes@undiksha.ac.id, \\ paseknugraha@undiksha.ac.id
}

\begin{abstract}
Abstrak
Di era modern ini perkembangan ilmu pengetahuan dan teknologi sangatlah pesat sehingga mengakibatkan perkembangan dunia industri juga semakin cepat. Mereka berlomba-lomba menemukan alat pendingin untuk memberikan mereka kenyamanan saat melakukan kegiatan-kegiatan didalam ruangan yang panas. Water Chiler adalah proses penanganan udara untuk mengontrol secara serempak terhadap temperatur, kelembaban, kebersihan dan distribusi untuk mencapai kondisi yang diinginkan. Refrigerant yang mengalir dalam siklus sekunder adalah fluida air (water) yang disirkulasikan dengan bantuan pompa. Fluida air pendingin (chilled water) inilah yang nantinya akan mengambil panas ruangan. Dilihat dari beberapa penelitian sebelumnya variasi fluida seperti coolant juga dapat mempengaruhi penyerapan panas dengan baik. Penelitian ini bertujuan untuk mengetahui pengaruh penggunaan variasi fluida air, coolant dan campuran air + coolant terhadap suhu yang dicapai Mini Water Chiler. Metode yang digunakan dalam penelitian ini adalah eksperimen dengan variable bebas yaitu air, coolant dan campuran air + coolant sedangkan variable terikat yaitu suhu. Pengujian dilakukan sebanyak 20 kali dan mencatat hasilnya tiap 20 menit. Dari hasil penelitian fluida campuran air + coolant mendapatkan suhu yang sangat optimal dibandingkan fluida air dan fluida coolant dengan rata-rata suhu di $A H U 1$ untuk fluida air: $13,43^{\circ} \mathrm{C}$, coolant: $12,52^{\circ} \mathrm{C}$ dan campuran air + coolant: $11,52^{\circ} \mathrm{C}, A H U 2$ untuk fluida air: $13,33^{\circ} \mathrm{C}$, coolant: $12,42^{\circ} \mathrm{C}$ dan campuran air + coolant: $11,42^{\circ} \mathrm{C}$ dan $A H U 3$ untuk fluida air: $13,23^{\circ} \mathrm{C}$, coolant: $12,32^{\circ} \mathrm{C}$ dan campuran air + coolant: $11,32^{\circ} \mathrm{C}$. Berdasarkan hasil penelitian tersebut fluida campuran air + coolant mendapatkan suhu yang sangat optimal dikarenakan karakteristik yang di miliki fluida air dan fluida coolant.
\end{abstract}

Kata-kata kunci : mini water chiler, variasi fluida, suhu optimal, pendingin.

\begin{abstract}
In this modern era the development of science and technology is so rapid that the development of the industrial world is also accelerating. They are competing to find refrigerators to provide them comfort while carrying out activities in a hot room. Water Chiler is an air handling process to simultaneously control temperature, humidity, cleanliness and distribution to achieve the desired condition. Refrigerant that flows in the secondary cycle is fluid water (water) which is circulated with the help of a pump. This chilled water will later take the heat of the room. Viewed from several previous studies fluid variations such as coolants can also affect heat absorption well. This study aims to determine the effect of using variations of water fluid, coolant and water + coolant mixture to the temperature achieved by Mini Water Chiler. The method used in this study is an experiment with independent variables namely water, coolant and water + coolant mixture while the dependent variable is temperature. The test is done 20 times and records the results every 20 minutes. From the results of the fluid mixture + coolant research get a very optimal temperature compared to water fluid and coolant fluid with an average temperature in AHU 1 for water fluid: $13.43^{\circ} \mathrm{C}$, coolant: $12.52^{\circ} \mathrm{C}$ and water mixture + coolant: $11.52^{\circ} \mathrm{C}$, AHU 2 for water fluid: $13,33^{\circ} \mathrm{C}$, coolant: $12,42^{\circ} \mathrm{C}$ and mixture of water + coolant: $11,42^{\circ} \mathrm{C}$ and AHU 3 for water fluid: $13,23^{\circ} \mathrm{C}$, coolant: $12,32^{\circ} \mathrm{C}$ and water mixture + coolant: $11,32^{\circ} \mathrm{C}$. Based on the results of this study, the mixture of water + coolant fluid gets a very optimal temperature due to the characteristics possessed by water fluid and coolant fluid.

Keywords: mini water chiller, fluid variations, optimal temperature, coolant.
\end{abstract}




\section{Pendahuluan}

Mini Water Chiler adalah mesin pendingin rancangan mahasiswa prodi pendingin jurusan Pendidikan Teknik Mesin undiksha, yang memiliki fungsi hampir sama dengan mesin water chiler pada umumnya namun pada rancangan ini mesin water chiler dibuat secara mini atau prototype, mesin ini mempunyai ukuran rangka dengan panjang $100 \mathrm{~cm}$, lebar $50 \mathrm{~cm}$, dan tinggi 130 $\mathrm{cm}$. Mini Water Chiler dirancang dengan memodifikasi AC Split, kapasitas kompresor yang digunakan adalah $1 \mathrm{PK}$. Kompresor 1PK digunakan karena kapasitas ruangan atau AHU tidak terlalu besar. Pada Chiled water tank supply menggunakan kaca yang dilapasi steroform, tujuannya memakai kaca sebagai Chiled water tank supply adalah untuk memudahi kepada pengamat untuk mengamati cara kerja evaporator yang direndam didalam Chiled water tank supply, ukuran Chiled water tank supply yaitu dengan panjang $84 \mathrm{~cm}$, tinggi $29 \mathrm{~cm}$, dan lebar $28 \mathrm{~cm}$. Untuk ruangan yang didinginkan menggunakan 3 ruangan mini yang dibuat menggunakan steroform, panjang ruangan yaitu $30 \mathrm{~cm}$, lebar $33 \mathrm{~cm}$, dan tinggi $50 \mathrm{~cm}$.

\section{Kompresor}

Kompresor pada mesin pendingin Mini Water Chiler merupakan jantung dari sistem refrigerasi yang berfungsi untuk mensirkulasikan gas refrigerant atau freon dalam sistem chiler, kompresor juga berfungsi sebagai penghisap uap refrigerant yang keluar dari evaporator, kompresor pada Mini Water Chiler memakai kompresor dengan kapasitas 1PK.

\section{Kondensor}

Komponen berikutnya pada Mini Water Chiler adalah kondensor, kondensor berfungsi sebagai pemindah panas dari sistem refrigerasi, gas atau uap refrigerant yang memiliki temperatur tinggi akan diserap lalu dihembuskan oleh fan yang ada pada kondensor sehingga menyebakan uap refrigerant mengembun menjadi cair.

\section{Katup Ekspansi}

Pada Mini Water Chiler alat ekspansi berfungsi untuk menurunkan tekanan gas refrigerant, pada alat ekspansi ini terjadi perubahan tekanan tinggi ke tekanan rendah. Selain itu katup eksapansi juga berfungsi sebagai pengontrol refrigerant yang masuk ke dalam evaporator.

\section{Evaporator}

Evaporator pada Mini Water Chiler adalah komponen yang memiliki fungsi untuk penyerap kalor air pada Box Mini Water Chiler. Evaporator pada Mini Water Chiler direndam pada Chiled water tank supply sehingga air yang melewati evaporator akan mengalami penurunan temperatur.

\section{Pompa Sirkulasi}

Pompa sirkulasi pada Mini Water Chiler berfungsi untuk mensirkulasikan air yang berada pada Box Mini Water Chiler menuju ke $A H U$ (Air Handling Unit).

\section{AHU (Air Handling Unit)}

AHU merupakan alat penukar kalor antara air dingin dengan udara, pada sistem ini, air dingin yang melewati evaporator yang sudah dimodifikasi di $A H U$ yang berada di dalam ruangan dihembuskan oleh fan pada $A H U$, sehingga membuat suhu di dalam ruangan menjadi dingin.

\section{Pipa}

Pipa yang digunakan pada Mini Water Chiler adalah pipa tembaga, pipa memiliki fungsi sebagai sistem instalasi untuk tempat mengalirnya media - media pendingin pada Mini Water Chiler.

\section{Solenoid Valve}

Solenoid pada Mini Water Chiler sebagai katup otomatis yang berfungsi untuk mengaliri atau menghentikan laju aliran air yang di pompa menuju $A H U$ jika sudah mencapai suhu yang diinginkan.

\section{Chiled Water Tank Supply}

Chiled water tank supply berfungsi sebagai wadah atau tempat penampung air yang akan didinginkan maupun air yang sudah melewati $A H U$, didalam chiled water tank supply juga terdapat evaporator yang terendam, dan juga pompa sirkulasi air.

\section{Cara Kerja Mini Water Chiler}

Pada Water Chiler terdapat 2 siklus refrigerasi yang saling berkaitan yaitu siklus 
refrigerasi primer dan siklus refrigerasi sekunder. Pada siklus refigerasi primer, refrigerant disirkulasikan oleh 4 komponen utama sistem refrigerasi uap, yaitu adalah kompresor, kondensor, ekspansi, dan evaporator untuk mendinginkan air di dalam box water chiler. Sedangkan siklus refigerasi sekunder adalah siklus dimana fluidanya adalah air yang sudah didinginkan pada siklus refrigerasi primer kemudian dialirkan ke AHU (Air Handling Unit) untuk mendinginkan ruangan, agar lebih jelas, berikut adalah 2 siklus refrigerasi pada Water Chiler :

1) Siklus Refrigerasi Primer

a. Proses Kompresi

Proses kompresi ini adalah proses dimana redrigerant yang awalnya berwujud gas, bertemperatur dan bertekenan rendah masuk ke dalam kompresor, kemudian di dalam kompresor refrigerant ini dimampatkan atau dikompresikan tetap dalam wujud gas dan mempunyai tekanan dan temperatur yang tinggi setelah itu dialirkan menuju evaporator.

b. Proses Kondensasi

Proses kondensasi ini adalah proses dimana refrigerant yang keluar dari kompresor dalam wujud gas bertekanan dan temperatur yang tinggi dialirkan ke kondensor, kemudian pada kondensor terjadi perubahan fase refrigerant yang dimana awalnya berwujud gas menjadi cair, setelah di kondensasikan refrigerant memiliki temperatur yang lebih rendah dan tekanan yang masih tinggi, setelah itu refrigerant dialirkan ke alat ekspansi.

c. Proses Ekspansi (Penurunan Tekanan)

Proses Ekspansi ini adalah proses dimana refrigerant mengalami penurunan tekanan, didalam alat ekspansi terjadi penurunan tekanan gas sehingga refrigerant yang berwujud cair memiliki tekanan yang rendah dan temperatur yang rendah. Kemudian dialirkan ke evaporator. d. Proses Evaporasi

Proses evaporasi adalah proses dimana refrigerant yang berwujud cair yang bertekanan dan bertemperatur yang rendah dimanfaatkan untuk mendinginkan media air yang berada di dalam box water chiler (evaporator direndam didalam box). Karena air yang melewati evaporator bersuhu lebih tinggi dibandingkan dengan suhu refrigerant maka terjadi perubahan wujud refrigerant dari fase cair menjadi fase gas karena terjadinya penyerapan kalor, setelah itu refrigerant dialirkan ke kondensor untuk di kondensasikan, setelah itu kembali lagi ke kompresor, proses ini akan terjadi berulang-ulang sampai suhu di dalam ruangan tercapai sesuai yang diatur.

2) Siklus Refrigerasi Sekunder

Setelah mengalami siklus refrigerasi primer sehingga air yang berada didalam Box Water Chiler menjadi dingin kemudian selanjutnya dilakukan siklus refrigerasi sekunder. Siklus ini diawali dengan pemompaan air dingin yang berada di box water chiler ke masing-masing AHU (Air Handling Unit) dan disirkulasi menuju evaporator yang sudah dimodifikasi di $A H U$. Selanjutnya udara dihembuskan oleh fan AHU untuk menghasilkan udara yang dingin. Pada proses tersebut mengalami penarikan atau penyerapan kalor yang ada didalam ruangan sehingga temperatur air dingin yang melewati evaporator yang sudah dimodifikasi di $A H U$ menjadi naik karena mendapatkan kalor dari udara. Kemudian setelah melewati $A H U$, air mengalir kembali ke box water chiler untuk didinginkan kembali oleh evaporator. Siklus ini akan berulang - ulang selama sistem pendingin bekerja untuk mendinginkan ruangan.

\section{Metode Penelitian}

Metode yang akan digunakan dalam penelitian ini adalah metode eksperimen. Metode eksperimen merupakan bagian dari metode kuantitatif, dan memiliki ciri khas tersendiri terutama dengan adanya kelompok kontrol. Dalam bidang sains, penelitian-penelitian dapat menggunakan desain eksperimen karena variabel-variabel 
dapat dipilih dan variabel-variabel lain yang dapat mempengaruhi proses eksperimen itu dapat dikontrol secara ketat. Sehingga dalam metode ini, peneliti memanipulasi paling sedikit satu variabel, mengontrol variabel lain yang relevan, dan mengobservasi pengaruhnya terhadap variabel terikat. Manipulasi variabel bebas inilah yang merupakan salah satu karakteristik yang membedakan penelitian eksperimental dari penelitian-penelitian lain. Dalam penelitian ini terdapat tiga variabel bebas dan satu variabel terikat yaitu:

1. Variasi fluida pendingin:
a. Air
b. Coolant
c. Campuran air + coolant

2. Suhu

Obyek yang digunakan dalam penelitian ini adalah Mesin Pendingin Mini Water Chiler dengan mengganti media air pendinginannya diharapkan menghasilkan pencapaian suhu optimal dan mendapat suhu yang lebih rendah dari pendinginan standarnya. Alat yang digunakan dalam penelitian ini adalah Mini Water Chiler dan bahan yang digunakan adalah air murni dan coolant.

Prosedur dalam penelitian ini yang pertama adalah penyusunan alat penelitian yang dimana alam penelitian ini seluruh pengambilan data dilakukan dengan mencatat hasil pengamatan pada thermostat digital. Sebelum dilaksanakan penelitian, terlebih dulu melakukan persiapan menyusun alat perlengkapan penelitian. Sebelum menyusun alat, dilakukan pengecekan kondisi mesin pendingin Mini Water Chiler. Yang kedua ada tahapan penelitian. Tahapan yang dilakukan dalam pengujian adalah sebagai berikut:

1. Tahapan Persiapan Pengujian

Setelah persiapan alat, selanjutnya pemasangan alat uji yaitu thermostart digital

2. Tahap Pengujian

Tahapan hasil pengujian dapat diperinci sebagai berikut :

a. Mini Water Chiler dengan jenis fluida yang akan diteliti

b. Menghidupkan mesin

c. Memulai pengujian atau proses pengambilan data dengan thermostart dengan mencari suhu tiap 20 menit. d. Mencatat suhu yang dihasilkan tiap 20 menit

e. Hasil diambil dengan 20 kali pengulangan

f. Mematikan mesin.

3. Akhir pengujian

Setelah proses pengujian atau pengambilan data selesai, langkah selanjutnya adalah mematikan mesin dan merapikan peralatan-peralatan yang digunakan selama proses pengambilan data. Pengolahan data penelitian. Setelah mendapat hasil penelitian dilakukan pengolahan menggunakan Aplikasi SPSS.

Metode pengumpulan data merupakan faktor penting demi keberhasilan penelitian. Hal ini berkaitan dengan bagaimana cara mengumpulkan data, siapa sumbernya, dan apa alat yang digunakan. Jenis sumber data adalah mengenai dari mana data diperoleh. Apakah data diperoleh dari sumber langsung (data primer) atau data diperoleh dari sumber tidak langsung (data sekunder). Dalam penelitian ini teknik pengumpulan data yang digunakan yaitu : teknik observasi dan tekni dokumentasi.

Teknik analisis data. Pada penelitian ini menggunakan analisis varians satu jalur (ANAVA A). Anava satu jalur (satu jalan/ANAVA A) ini digunakan menganalisis data dari satu variable klasifikasi sampel dan sebelum analisis data pertama yang harus dilakukan adalah uji prasyarat analisi yang meliputi uji normalitas data dan uji homogenitas data, 


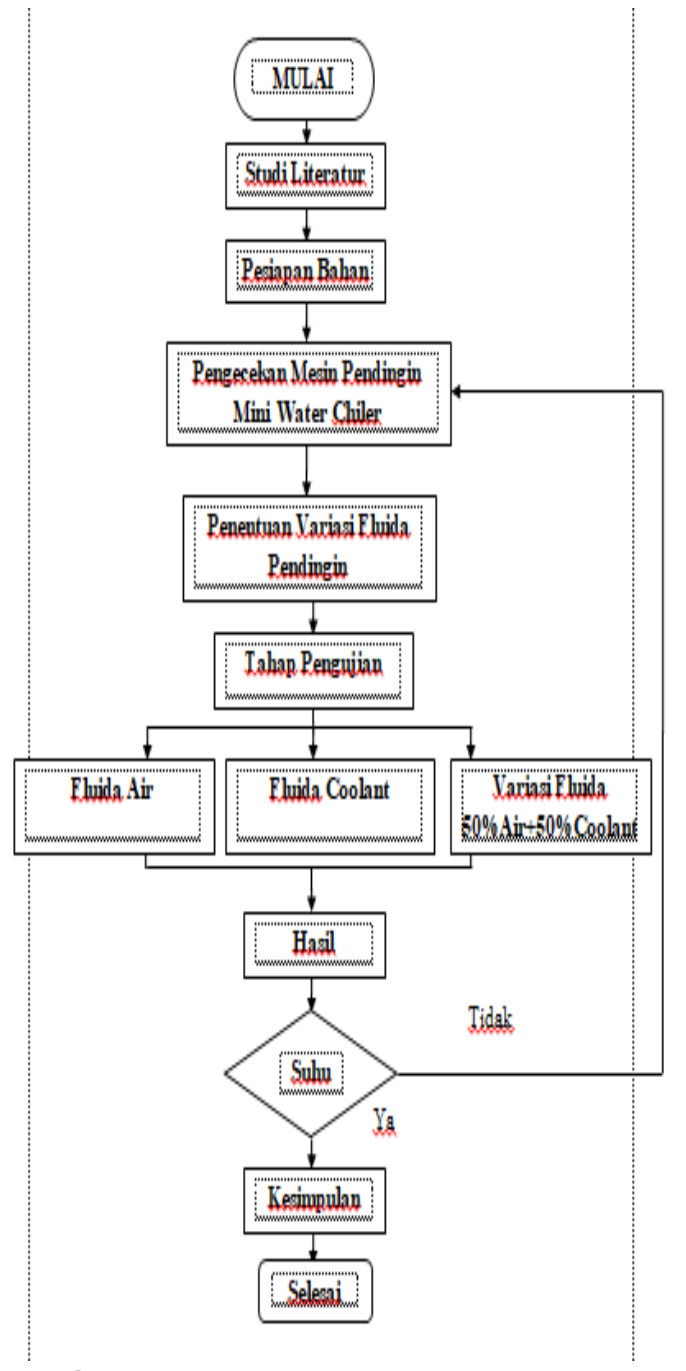

Gambar 1. Diagram Alir Penelitian

Tahapan dalam penelitian ini dapat dijabarkan sebagai berikut : (a) Studi kepustakaan/literatur untuk menggali teori dasar mengenai kompresor, kondensor, katup ekspansi, evaporator, pompa sirkulasi, AHU (Air Handling Unit), pipa, solenoid valve, chiled water tank supply. (b) Pemilihan dan pengumpulan komponen untuk pembuatan mesin pendingin Mini Water Chiler. (c) Adapun komponen yang perlu disiapkan seperti : kompresor, kondensor, katup ekspansi, evaporator, pompa sirkulasi, AHU (Air Handling Unit), pipa, solenoid valve, chiled water tank supply. (d) Proses pembuatan dan perakitan prototype mesin Mini Water Chiler sesuai dengan rancangan yang sudah di buat. (d) kemudian melakukan pengujian dengan menggunakan variasi fluida air, coolant, dan campuran air + coolant. (e) Pengambilan data dengan melakukan pengukuran suhu yang dihasilkan oleh Mini Water Chiler dengan menggunakan thermostat digital sehingga mendapatkan hasil yang dapat menunjang penelitian ini.

\section{Alat dan Bahan}

Alat dan bahan yang digunakan pada penelitian yang akan dilaksanakan ini dapat dipaparkan sebagai berikut:

a. Mesin Pendingin Mini Water Chiler

b. Air Murni

c. Coolant

\section{Hasil dan Pembahasan}

1) Hasil Capaian Suhu Mini Water Chiler di AHU 1 menggunakan variasi fluida air, coolant dan campuran air + coolant

Dari tabel data hasil pengujian diatas suhu yang dicapai Mini Water Chiler di AHU 1 menggunakan variasi fluida air, coolant dan campuran air + coolant bervariasi. Ratarata suhu yang dicapai:
a) Air
$: 13,43^{\circ} \mathrm{C}$
b) Coolant
$: 12,52^{\circ} \mathrm{C}$
c) Campuran air + coolant : $11,52^{\circ} \mathrm{C}$

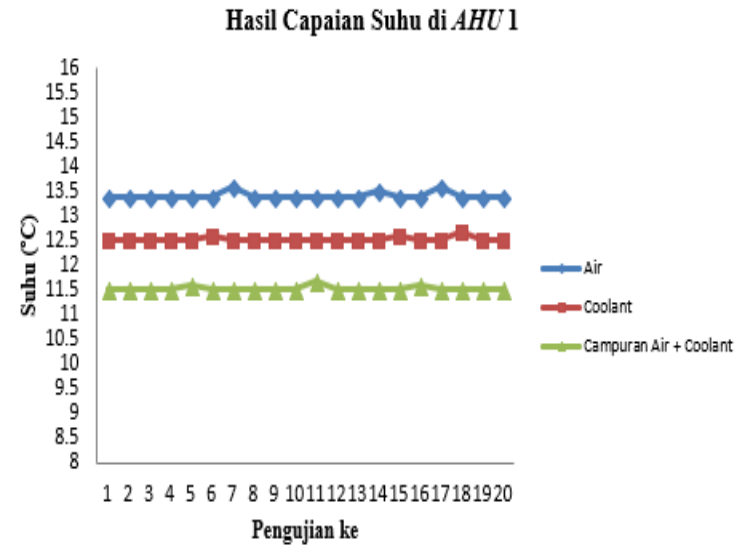

Gambar 2. Grafik Hasil Capaian Suhu di AHU 1 Mini Water Chiler Menggunakan Fluida Air, Coolant dan Campuran Air + Coolant

2) Hasil Capaian Suhu Mini Water Chiler di $A H U 2$ menggunakan variasi fluida air, coolant dan campuran air + coolant

Dari tabel data hasil pengujian diatas suhu yang dicapai Mini Water Chiler di AHU 2 menggunakan variasi fluida air, coolant dan campuran air + coolant bervariasi. Ratarata suhu yang dicapai: 

a) Air
$: 13,33^{0}$
b) Coolant
$: 12,42^{\circ} \mathrm{C}$
c) Campuran air + coolant : $11,42^{\circ} \mathrm{C}$

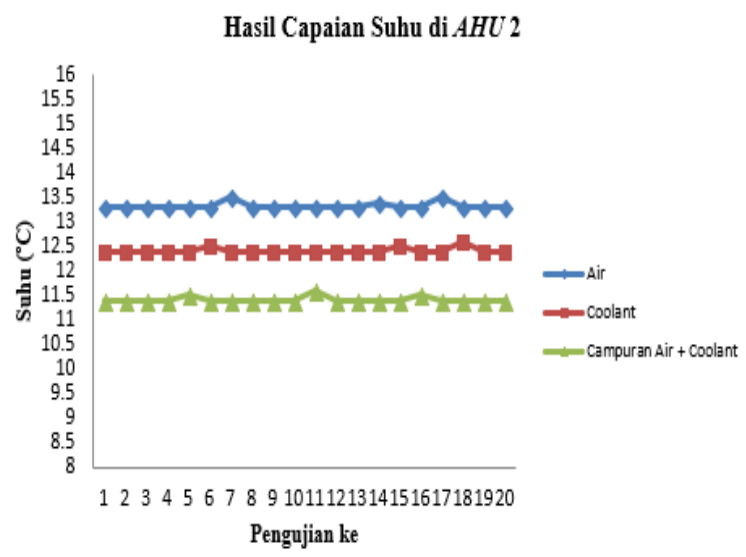

Gambar 3. Grafik Hasil Capaian Suhu di AHU 2 Mini Water Chiler Menggunakan Fluida Air, Coolant dan Campuran Air + Coolant

3) Hasil Capaian Suhu Mini Water Chiler di AHU 3 menggunakan variasi fluida air, coolant dan campuran air + coolant

Dari tabel data hasil pengujian diatas suhu yang dicapai Mini Water Chiler di AHU 3 menggunakan variasi fluida air, coolant dan campuran air + coolant bervariasi. Ratarata suhu yang dicapai:
a) Air
$: 13,23{ }^{\circ} \mathrm{C}$
b) Coolant $: 12,32^{\circ} \mathrm{C}$
c) Campuran air + coolant
$: 11,32^{\circ} \mathrm{C}$

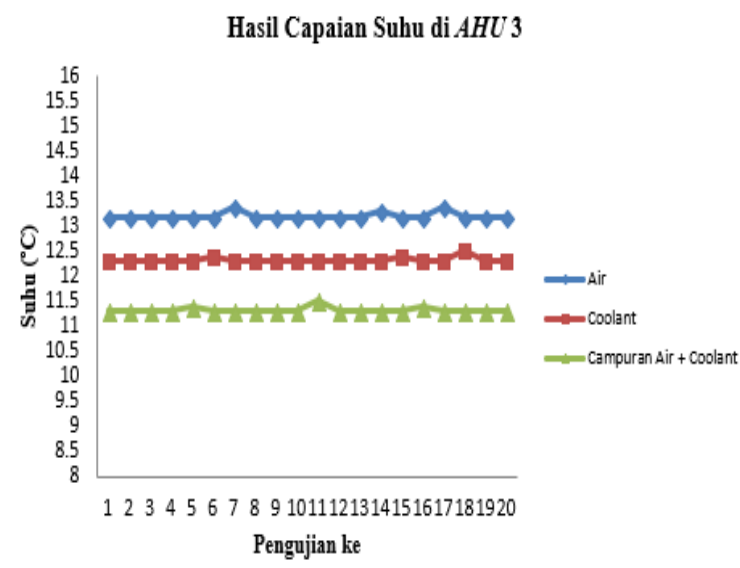

Gambar 4. Grafik Hasil Capaian Suhu di AHU 3 Mini Water Chiler Menggunakan Fluida Air, Coolant dan Campuran Air + Coolant

\section{Pembahasan}

Berdasarkan penelitian sebelumnya, bahwa volume fluida berpengaruh terhadap capaian suhu optimal,maka peneliti bermaksud untuk memvariaskan fluida pada Mini water Chiler untuk mengoptimalkan capaian suhunya. Setelah melakukan analisa berdasarkan data dan grafik mengenai suhu ditemukan bahwa volume fluida mempunyai pengaruh yang signifikan terhadap capaian suhu optimal dari Mini Water Chiler. Ini dikarenakan fluida mempunyai pengaruh yang signifikan terhadap suhu capaian Mini Water Chiler. Penggunaan campuran air + coolant menghasilkan suhu terendah. Ini dikarenakan karakteristik yang ada pada air dan coolant. Hal ini juga dibuktikan dengan analisa berdasarkan table uji lanjut Tukey didapatkan bahwa penggunaan variasi fluida air, coolant dan campuran air + coolant berpengaruh terhadap suhu optimal. Dan penggunaan fluida campuran air + coolant mendapatkan suhu yang sangat optimal dibandingkan dengan menggunakan fluida air dan coolant. Dengan rata-rata suhu di AHU 1 untuk fluida air: $13,43^{\circ} \mathrm{C}$, coolant: $12,52^{\circ} \mathrm{C}$ dan campuran air + coolant: $11,52^{\circ} \mathrm{C}, A H U 2$ untuk fluida air: $13,33^{\circ} \mathrm{C}$, coolant: $12,42^{\circ} \mathrm{C}$ dan campuran air + coolant: $11,42^{\circ} \mathrm{C}$ dan $A H U 3$ untuk fluida air: $13,23^{\circ} \mathrm{C}$, coolant: $12,32^{\circ} \mathrm{C}$ dan campuran air + coolant: $11,32^{\circ} \mathrm{C}$.

\section{Kesimpulan}

Adapun kesimpulan yang dapat penulis berikan dari pengaruh kecepatan aliran fluida terhadap capaian suhu optimal hasil mesin pendingin Mini Water Chiler adalah sebagai berikut :

1. Dari analisis data yang dilakukan fluida campuran air + coolant mendapatkan suhu yang sangat optimal di bandingkan fluida air dan fluida coolant. Ini di karenakan karakteristik yang dimiliki air dan coolant. Air memiliki karakteristik yaitu: perubahn suhu berlangsung secara lambat, air merupakan pelarut yang baik, air memerlukan panas yang tinggi dalam proses penguapan, air memiliki viskositas yang kurang kental. Sedangkan coolant memiliki karakteristik yaitu: titik didih lebih tinggi, Titik beku lebih rendah, tidak korosif, tidak sebabkan kerak 
kalsium, lebih efektif menyerap panas, viskositas lebih kental. Karakteristik ini yang menyebabkan fluida campuran air + coolant mendapatkan suhu yang sangat optimal dibandingkan dengan fluida air dan fluida coolant, karana campuran tersebut akan membentuk karakteristik yang baru.

2. Analisa berdasarkan table uji lanjut Tukey didapatkan bahwa penggunaan variasi fluida air, coolant dan campuran air + coolant berpengaruh terhadap suhu optimal. Dan penggunaan fluida campuran air + coolant mendapatkan suhu yang sangat optimal dibandingkan dengan menggunakan fluida air dan coolant. Dengan rata-rata suhu di $A H U 1$ untuk fluida air: $13,43^{\circ} \mathrm{C}$, coolant: $12,52^{\circ} \mathrm{C}$ dan campuran air + coolant: $11,52^{\circ} \mathrm{C}, A H U 2$ untuk fluida air: $13,33^{\circ} \mathrm{C}$, coolant $12,42^{\circ} \mathrm{C}$ dan campuran air + coolant: $11,42^{\circ} \mathrm{C}$ dan $A H U 3$ untuk fluida air: $13,23^{\circ} \mathrm{C}$, coolant: $12,32^{\circ} \mathrm{C}$ dan campuran air + coolant: $11,32^{\circ} \mathrm{C}$.

\section{Saran}

Adapun saran yang penulis dapat sampaikan adalah sebagai berikut :

Berdasarkan hasil penelitian ini untuk mendapat suhu optimal pada rancangan mesin pendingin Mini Water Chiller maka fluida yang digunakan adalah fluida campuran air + coolant.

\section{Daftar Pustaka}

Arikunto. 2006. Metodelogi Penelitian. Hal: 158

Dantes, Nyoman. 2014. Analisis Dan Desain Eksperimen (Disertai Contoh Penerapan Analisis Data). Singaraja : Program Pascasarjana Undiksha.

Hadi B1, Aris Zainul Muttaqin 2. 2014. Efektivitas Variasi Campuran Radiator Coolant Dengan Air Terhadap Laju Pembuangan Panas. Jember: Universitas Jember.

lan Antoni1, Nely Ana Mufarida2, Sihmanto3. 2014. Analisis Perpindahan Panas Dan

Pemakaian Bahan Bakar Terhadap Variasi Campuran Radiator

Coolant Dan Air. Jember : Universitas Muhammadiyah Jember.

Koyan, I Wayan. 2012. Statistika Pendidikan (Teknik Analisis Data
Kuantitatif). Singaraja:Universitas Pendidikan Ganesha (UNDIKSHA). Kusuma, Kadek Doni Hendra. 2018. Pengaruh Variasi Volume Fluida Pendingin Terhadap Capaian Suhu Optimal Hasil Rancangan Coolbox Zero Pollution. Singaraja : Universitas Pendidikan Ganesha (UNDIKSHA).

Nugroho, Agung. 2009. Laju Perpindahan Panas Pada Radiator Dengan Fluida Campuran 80\% Air Dan 20\% Radiator Coolant Pada Putaran Konstan. Demak:Universitas Sultan Fatah (UNISFAT).

Pawitra, I Ketut Pande. 2018. Pengaruh Variasi Fluida Pendingin Terhadap Capaian Suhu Optimal Hasil Rancangan Coolbox Zero Pollution. Singaraja : Universitas Pendidikan Ganesha (UNDIKSHA).

Riandika, Putu. 2018. Pengaruh Kecepatan Aliran Fluida Terhadap Capaian Suhu Optimal Hasil Rancangan Coolbox Zero Pollution. Singaraja : Universitas Pendidikan Ganesha (UNDIKSHA).

Sumanto, MA. Pertama. 2000. Dasar-Dasar Mesin Pendingin. Yogyakarta : Penerbit Andi. 979-533-604-5.

Sujadi. 2002. Metodologi Penelitian Pendidikan. Jakarta : Rineka Cipta.

Supardi. 2006. Metodologi Penelitian. Mataram : Yayasan Cerdas Press.

Neji, Tio. 2013. Mesin Pendingin Chiler. Acedemia. 